\title{
Outcome of Epstein-Barr virus-associated primary breast cancer
}

\author{
CHAFIKA MAZOUNI ${ }^{1,2}$, FRÉDÉRIC FINA ${ }^{1}$, SYLVIE ROMAIN ${ }^{1}$, L'HOUCINE OUAFIK $^{1}$, \\ PASCAL BONNIER $^{3}$ and PIERRE-MARIE MARTIN ${ }^{3}$
}

\author{
${ }^{1}$ Transfer Laboratory of Biological Oncology, Public Assistance Hospitals of Marseille, \\ Northern Faculty of Medicine, Marseille; ${ }^{2}$ Department of General Surgery, Institute Gustave Roussy, Villejuif; \\ ${ }^{3}$ Institute of Surgery and Gynecological and Breast Oncology, Beauregard Hospital, Marseille, France
}

Received September 18, 2014; Accepted November 14, 2014

DOI: $10.3892 / \mathrm{mco} .2014 .459$

\begin{abstract}
The presence of the Epstein-Barr-virus (EBV) has been reported to be a pathogenic factor in breast cancer (BC). We previously demonstrated the aggressiveness of EBV-positive BC. The purpose of the present study was to evaluate the effect of $\mathrm{EBV}$ on the prognosis of $\mathrm{BC}$ according to the $\mathrm{BC}$ phenotype. A total of 117 patients with primary $\mathrm{BC}$ previously tested for the presence of EBV were evaluated. The presence of the virus was evaluated in breast specimens using quantitative PCR (qPCR). Disease-free survival (DFS) and overall survival (OS) were evaluated for 4 molecular subtypes, namely luminal A and B (lumA and lumB, respectively), human epidermal growth factor receptor 2 (HER2) and triple-negative (TN) subtypes and according to the EBV status. EBV positivity was observed in $32.5 \%$ of the cases. TN, HER2 and lumB tumours were more frequent among EBV-BC cases $(\mathrm{P}=0.02)$. The DFS rates were different between $\mathrm{BC}$ subtypes $(\mathrm{P}=0.002)$, but the differences were not statistically significant when the cases were stratified according to the EBV status ( $\mathrm{P}=0.08$ for EBV-negative and 0.06 for EBV-positive cases). The OS rates were similar for $\mathrm{BC}$ subtypes $(\mathrm{P}=0.50)$ and when the cases were stratified according to the EBV status $(\mathrm{P}=0.16$ and $\mathrm{P}=0.67$ for $\mathrm{EBV}$-positive and -negative cases, respectively). EBV was not associated with DFS or OS, in contrast to BC phenotypes, tumour size or nodal status. Therefore, EBV positivity was found to exert no effect on survival, despite its association with aggressive $\mathrm{BC}$ phenotypes.
\end{abstract}

\section{Introduction}

Breast cancer (BC) heterogeneity is associated with diverse causal factors, such as heredity, environmental exposure, hormonal impregnation and infectious agents. Among these factors, viruses are regularly implicated in the pathogenesis of

Correspondence to: Dr Chafika Mazouni, Department of General Surgery, Institute Gustave Roussy, Cancer Campus, Grand Paris, 114 Edouard Vaillant street, 94805 Villejuif, France

E-mail: chafika.mazouni@gustaveroussy.fr

Key words: breast cancer, Epstein-Barr virus, molecular types, survival cancer, although the results of different studies have been inconsistent (1). In particular, the Epstein Barr virus (EBV) is clearly associated with nasopharyngeal cancer, but a causal relationship with BC was also demonstrated in the mid-1990s (2). The reported incidence of EBV-positive $\mathrm{BC}$ varies according to the technique used and the targeted viral genomic regions (1). We previously demonstrated the presence of EBV in $\leq 30 \%$ of $\mathrm{BC}$ specimens $(3,4)$. Of note, EBV-related BC were found to be associated with more aggressive patterns (4).

A previous study published by Perou et al using genomic profiling has made a major contribution to the understanding of BC heterogeneity (5). A new classification is currently available, based on 5 expression signatures revealing distinct patterns. The BC subtypes clearly reflect groups with different outcomes and response to chemotherapy (6). Using clinicopathological factors, such as hormone receptors (HRs), human epidermal growth receptor 2 (HER2) and grade or Ki67, this intrinsic BC classification may be determined in routine practice (7).

Several questions regarding the significance of EBV in $\mathrm{BC}$ remain challenging and the association with oncogenesis remains obscure. An adverse outcome for EBV-positive BC was previously suggested $(8,9)$. The purpose of our study was to evaluate the prognosis of EBV-positive BC. In addition, we incorporated the $\mathrm{BC}$ subtype classification in order to refine the evaluation of the prognosis.

\section{Patients and methods}

Patients and methods. All the BCs investigated were identified through a prospective institutional database search. All the patients with primary BC had undergone surgery at the Department of Obstetrics and Gynaecology, Conception Hospital, Marseille, France. BC tissue samples were prospectively collected between 1981 and 1998. The indications according to the department protocols for adjuvant treatment were based on the tumour size, patient age, grading, HR status and nodal status. Patients who had undergone conservative treatment had also received breast radiotherapy. Radiotherapy had also been delivered to the internal mammary lymph nodes in cases with centrally or internally located tumours and to the supraclavicular and internal mammary lymph nodes in cases with positive axillary lymph nodes. Hormone therapy had been administered for 5 years to all HR-positive tumours. The steroid HR (oestrogen 
Table I. Patient and tumour characteristics.

\begin{tabular}{lc}
\hline Characteristics & $\begin{array}{c}\text { Patient no. }(\%) \\
(\mathrm{n}=117)\end{array}$ \\
\hline Age at diagnosis, years & \\
[Median (range) & $57(36-79)$ \\
$<50$ & $37(31.6)$ \\
$\geq 50$ & $80(68.4)$ \\
pTumour size & \\
T1 & $68(58.1)$ \\
T2 & $37(31.6)$ \\
T3 & $12(10.3)$ \\
Lymph node status & \\
Negative & $66(56.4)$ \\
Positive & $51(43.6)$ \\
SBR grade & \\
I-II & $79(67.5)$ \\
III & $38(32.5)$ \\
Oestrogen receptor status & \\
Positive & $89(76.1)$ \\
Negative & $28(23.9)$ \\
Progesterone receptor status & \\
Positive & $77(65.8)$ \\
Negative & $40(34.2)$ \\
HER2 overexpression & $22(18.8)$ \\
EBV positivity & $38(32.5)$ \\
&
\end{tabular}

HER2, human epidermal growth factor receptor 2; SBR, Scarff-Bloom-Richardson; EBV, Epstein-Barr-virus.

and progesterone receptor) status had initially been determined biochemically in cytosol fractions and then expressed quantitatively as fmol/mg protein (Abbott Laboratories, Diagnostic Division, Chicago, IL, USA). The EBV status had been determined using quantitative polymerase chain reaction (qPCR). The protocol was previously described $(3,4)$ and approved by Johi and Buehring (1), who consider our analytical chain as one of 4/30 EBV-positive studies that convincingly demonstrated the presence of EBV in $\mathrm{BC}$.

Statistical analysis. The differences in baseline characteristics between the EBV-negative and EBV-positive subgroups were summarized and compared using the Chi-square test (categorical variables) or the Student's t-test (continuous variables). Survival rates [overall survival (OS) and disease-free survival (DFS)] were measured from the date of surgery to the time of disease-related death or to the first clinical or radiographic evidence of recurrent disease. We plotted Kaplan-Meier curves for DFS and used the log-rank test to determine the univariate significance of the variables. All the analyses were performed using the SPSS software package version 21 (SPSS, Inc., Chicago, IL, USA). P-values $<0.05$ were considered to indicate statistically significant differences. All the reported P-values are two-sided.

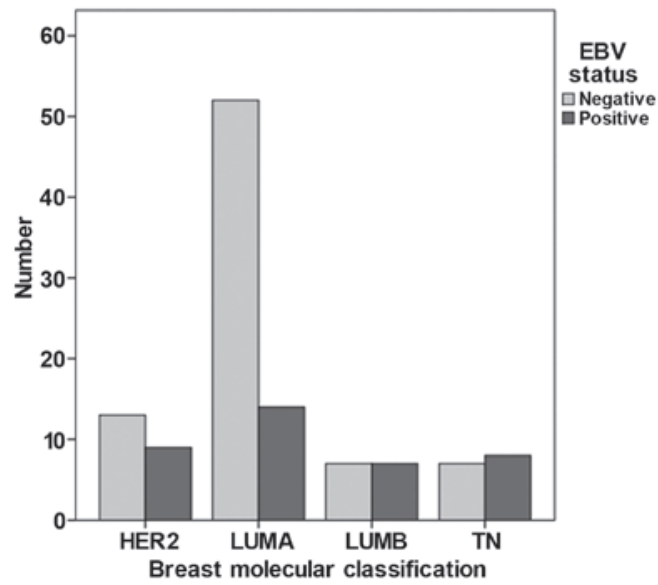

Figure 1. Breast cancer classified according to subtype and Epstein-Barr-virus (EBV) status. HER2, human epidermal growth factor receptor 2; lum, luminal; TN, triple-negative.

\section{Results}

Tumour characteristics. Our data demonstrated that the tumours in 38 of the 117 patients (32.5\%) exhibited positivity for EBV. The characteristics of the study population are summarized in Table I. The majority of the tumours were T1 (58.1\%), node-negative $(56.4 \%)$, grade I-II and HR+. The clinicopathological characteristics according to the EBV status are presented in Table II. A significant correlation was observed between viral positivity and grading in the univariate analysis. Thus, the frequency of grade III tumours was higher among EBV-positive $\mathrm{BC}$ cases. The oestrogen receptor status was of borderline significance. When $\mathrm{BC}$ was classified according to subtypes (Fig. 1), triple-negative (TN), HER2 and luminal B (lumB) tumours were more frequent among EBV-positive BC cases $(\mathrm{P}=0.02)$.

Survival. The results of the Kaplan-Meier estimation of OS and DFS revealed no difference in OS between EBV-positive and EBV-negative tumours $(\mathrm{P}=0.49)$. The probability of 5-year OS in patients with EBV-negative BC was $91.7 \%$ [95\% confidence interval (CI): 82.4-96.2\%], whereas it was $87.3 \%$ (95\% CI: 69.6-95.1\%) in patients with EBV-positive BC. Similarly, no difference was observed in DFS $(\mathrm{P}=0.19)$. The probability of 5-year DFS in patients with EBV-negative BC was 78.3\% (95\% CI: $66.5-86.4 \%$ ) vs. $64.5 \%$ (95\% CI: $44.7-78.7 \%$ ) in patients with EBV-positive BC (data not shown).

When these survival rates were stratified according to the molecular phenotype, the DFS rates differed among BC subtypes $(\mathrm{P}=0.002)$, but the difference did not reach statistical significance when they were stratified according to the EBV status $(\mathrm{P}=0.08$ for $\mathrm{EBV}$-negative and 0.06 for $\mathrm{EBV}$-positive $\mathrm{BC})$. The $\mathrm{OS}$ rates were similar among $\mathrm{BC}$ subtypes $(\mathrm{P}=0.50)$ and when they were stratified according to the EBV status $(\mathrm{P}=0.16$ and $\mathrm{P}=0.67$ for $\mathrm{EBV}$-positive and -negative cases, respectively) (data not shown).

The 5-year DFS in patients with EBV-positive BC was $67.5 \%$ (95\% CI: $45.4-100 \%$ ) for lumA, $41.7 \%$ (95\% CI: $14.7-100 \%$ ) for lumB, $46.9 \%$ (95\% CI: 21.5-100\%) for HER2 and 100\% for TN $\mathrm{BC}$. The 5-year DFS in patients with EBV-negative BC was 
Table II. Patient characteristics according to the EBV status of the tumours.

\begin{tabular}{|c|c|c|c|}
\hline Characteristics & $\begin{array}{l}\text { EBV-positive } \\
\quad(\mathrm{n}=38)\end{array}$ & $\begin{array}{l}\text { EBV-negative } \\
\quad(\mathrm{n}=79)\end{array}$ & P-value \\
\hline Age, years, no. (\%) & & & 0.20 \\
\hline$<50$ & $9(23.7)$ & $28(35.4)$ & \\
\hline$\geq 50$ & $29(76.3)$ & $51(64.6)$ & \\
\hline pTumour size (\%) & & & 0.65 \\
\hline $\mathrm{T} 1$ & $21(55.3)$ & $47(59.5)$ & \\
\hline $\mathrm{T} 2$ & $14(36.8)$ & $23(29.1)$ & \\
\hline T3 & $3(7.9)$ & 9 (11.4) & \\
\hline Lymph node status, no. (\%) & & & 0.33 \\
\hline Negative & $19(50.0)$ & $47(59.5)$ & \\
\hline Positive & $19(50.0)$ & $32(40.5)$ & \\
\hline SBR grade, no. (\%) & & & 0.02 \\
\hline I-II & $20(52.6)$ & $59(74.7)$ & \\
\hline III & $18(47.4)$ & $20(25.3)$ & \\
\hline Oestrogen receptor status, no. (\%) & & & 0.07 \\
\hline Positive & $25(65.8)$ & $64(81.0)$ & \\
\hline Negative & $13(34.2)$ & $15(19.0)$ & \\
\hline Progesterone receptor status, no. $(\%)$ & & & 0.21 \\
\hline Positive & $22(57.9)$ & $55(69.6)$ & \\
\hline Negative & $16(42.1)$ & $24(30.4)$ & \\
\hline HER2 overexpression, no. (\%) & $9(23.7)$ & $13(16.4)$ & 0.35 \\
\hline TK, no. $(\%)$ & & & 0.03 \\
\hline Low & $25(65.8)$ & $66(83.5)$ & \\
\hline High & $13(34.2)$ & $13(16.5)$ & \\
\hline \multicolumn{4}{|l|}{ BC subtypes, no. (\%) } \\
\hline Luminal A & $14(36.8)$ & $52(65.8)$ & \\
\hline Luminal B & 7 (18.4) & $7(8.9)$ & \\
\hline Triple-negative & $8(21.1)$ & $7(8.9)$ & \\
\hline HER2 & $9(23.7)$ & $13(16.4)$ & \\
\hline
\end{tabular}

EBV, Epstein-Barr-virus; SBR, Scarff-Bloom-Richardson; HER2, human epidermal growth factor receptor 2; TK, thymidine kinase; $\mathrm{BC}$, breast cancer.

$84.2 \%$ (5\% CI: $74.1-95.8 \%)$ for lumA, $71.4 \%$ (5\% CI: 44.7-100\%) for lumB, $55.6 \%$ (5\% CI: 32.5-95\%) for HER2 and $85.7 \%$ (5\% CI: $63.3-100 \%)$ for TN BC (data not shown).

According to the results of the Cox univariate analysis, EBV was not associated with $\mathrm{OS}$ [hazard ratio $(\mathrm{HR})=1.48, \mathrm{P}=0.49$ ], in contrast to tumour size $(\mathrm{HR}=9.77, \mathrm{P}=0.001)$ or nodal status $(\mathrm{HR}=3.98, \mathrm{P}=0.02)$. In this univariate analysis, $\mathrm{EBV}$ was not significantly correlated with $\mathrm{DFS}(\mathrm{HR}=1.33, \mathrm{P}=0.61)$, but was significantly associated with tumour size $(\mathrm{HR}=1.46, \mathrm{P}<0.001)$ and nodal positivity $(\mathrm{HR}=3.5, \mathrm{P}=0.03)$ (data not shown).

\section{Discussion}

Several converging studies have demonstrated the presence of EBV in BC. However, despite evidence on the presence of $\mathrm{EBV}$ in $\mathrm{BC}$ specimens, an oncogenic role for EBV has yet to be established and the significance of EBV-positive BC has not been fully elucidated.
Virus-related BC has a poor prognosis, particularly when multiple viruses are detected in breast specimens (8). We previously demonstrated that EBV-positive BC exhibits more aggressive characteristics $(3,4)$. Other authors corroborated our findings $(2,8)$; however, the effect on survival has not been extensively investigated. The subgroup analyses as a function of the BC phenotype confirmed that the EBV status exerted no effect on survival outcome (DFS or OS). Of note, in EBV-positive tumours, DFS was of borderline significance, with an adverse prognostic outcome for lumB and HER2 tumours. LumB and HER2 tumours were previously demonstrated to carry a poor prognosis (6).

There were certain limitations to our study. Our series was small, information was lacking on the adjuvant therapies administered and the treatments received were heterogeneous. In particular, the unavailability of trastuzumab therapy when the patients were treated may have significantly affected the prognosis of HER2 tumours. 
In response to published comments by Khan $\mathrm{G}$ et al (10) on our previous study (4) and in order to understand the discrepancies regarding the detection of viral genomic DNA in $\mathrm{BC}$, it is important to take into consideration the viral genomic load and the amount of DNA in the samples tested. Similarly, in tests for gene mutations in somatic samples, we cannot consider the limits of the detection method without taking into account the total amount of DNA tested. In this study, we demonstrated that the presence of EBV did not exert an adverse effect on the prognosis, or on OS and DFS. This finding is quite surprising, given the greater representation of high-grade and HER2 tumours, but significance was not demonstrated when survival estimates were stratified according to the EBV status ( $\mathrm{P}=0.08$ for EBV-negative and 0.06 for EBV-positive tumours), although the values were of borderline significance. It is noteworthy that TN, HER2 and lumB tumours were more frequent among EBV-positive BC cases $(\mathrm{P}=0.02)$. The implication of $\mathrm{EBV}$ in $\mathrm{BC}$ requires further investigation, which may be facilitated by the improvement of droplet digital PCR. The sensitivity of this technology is well suited to address these questions and, above all, the presence or absence of viral genome in tumours of epithelial origin.

The presence of EBV in BC is frequently reported and has been associated with more aggressive forms. However, the prognostic significance of EBV presence remains unclear. Future studies are required to identify the association of EBV presence and activity at the DNA level, as it has not been clearly determined whether EBV acts as an oncogene in BC.

\section{Acknowledgements}

The authors would like to thank Lorna Saint Ange for editing the manuscript.

\section{References}

1. Joshi D and Buehring GC: Are viruses associated with human breast cancer? Scrutinizing the molecular evidence. Breast Cancer Res Treat 135: 1-15, 2012.

2. Labrecque LG, Barnes DM, Fentiman IS and Griffin BE: Epstein-Barr virus in epithelial cell tumors: a breast cancer study. Cancer Res 55: 39-45, 1995.

3. Fina F, Romain S, Ouafik L, Palmari J, Ben Ayed F, Benharkat S, Bonnier P, Spyratos F, Foekens JA, Rose C, Buisson M, Gérard H, Reymond MO, Seigneurin JM and Martin PM: Frequency and genome load of Epstein-Barr virus in 509 breast cancers from different geographical areas. Br J Cancer 84: 783-790, 2001.

4. Mazouni C, Fina F, Romain S, Ouafik L, Bonnier P, Brandone JM and Martin PM: Epstein-Barr virus as a marker of biological aggressiveness in breast cancer. Br J Cancer 104: 332-337, 2011.

5. Perou CM, Sørlie T, Eisen MB, van de Rijn M, Jeffrey SS, Rees CA, Pollack JR, Ross DT, Johnsen H, Akslen LA, Fluge O, Pergamenschikov A, Williams C, Zhu SX, Lønning PE, Børresen-Dale AL, Brown PO and Botstein D: Molecular portraits of human breast tumours. Nature 406: 747-752, 2000.

6. Rouzier R, Perou CM, Symmans WF, Ibrahim N, Cristofanilli M, Anderson K, Hess KR, Stec J, Ayers M, Wagner P, Morandi P, Fan C, Rabiul I, Ross JS, Hortobagyi GN and Pusztai L: Breast cancer molecular subtypes respond differently to preoperative chemotherapy. Clin Cancer Res 11: 5678-5685, 2005.

7. Goldhirsch A, Wood WC, Coates AS, Gelber RD, Thürlimann B and Senn HJ; Panel members: Strategies for subtypes - dealing with the diversity of breast cancer: highlights of the St. Gallen International Expert Consensus on the Primary Therapy of Early Breast Cancer 2011. Ann Oncol 22: 1736-1747, 2011.

8. Tsai JH, Hsu CS, Tsai CH, Su JM, Liu YT, Cheng MH, Wei JC, Chen FL and Yang CC: Relationship between viral factors, axillary lymph node status and survival in breast cancer. J Cancer Res Clin Oncol 133: 13-21, 2007.

9. Aguayo F, Khan N, Koriyama C, González C, Ampuero S, Padilla O, Solís L, Eizuru Y, Corvalán A and Akiba S: Human papillomavirus and Epstein-Barr virus infections in breast cancer from chile. Infect Agent Cancer 6: 7, 2011.

10. Khan G, Philip PS and Al Ashari M: Is Epstein-Barr virus associated with aggressive forms of breast cancer? Br J Cancer 104: 1362-1363, 2011. 